\title{
Adolescent reproductive health challenges among schoolgirls in southeast Nigeria: role of knowledge of menstrual pattern and contraceptive adherence
}

This article was published in the following Dove Press journal:

Patient Preference and Adherence

24 August 2015

Number of times this article has been viewed

\author{
Leonard Ogbonna Ajah' \\ Ebele Samuel Onubogu' \\ Okechukwu Bonaventure \\ Anozie' \\ Lucky Osaheni Lawani' \\ Chukwuemeka Anthony \\ lyoke ${ }^{2}$ \\ Emeka Ogah Onwe ${ }^{3}$ \\ Monique Iheoma $\mathrm{Ajah}^{4}$ \\ 'Department of Obstetrics and \\ Gynaecology, Federal Teaching \\ Hospital, Abakaliki, ${ }^{2}$ Department \\ of Obstetrics and Gynaecology, \\ University of Nigeria Teaching \\ Hospital, Ituku-Ozalla, ${ }^{3}$ Department \\ of Paediatrics, ${ }^{4}$ Well Women Centre, \\ Federal Teaching Hospital, Abakaliki, \\ Nigeria
}

Background: Reproductive health services in the form of adolescent health and contraceptive services are fundamental in the prevention of a high incidence of teenage pregnancy. The purpose of this study was to determine the age at menarche, menstrual pattern, and awareness of and use of modern contraception among secondary school girls in Abakaliki, Nigeria.

Subjects and materials: This was a cross-sectional study in which self-administered questionnaires were completed by 482 adolescent girls at two girls' secondary schools between August and September 2012.

Results: The mean age at menarche was $13.13 \pm 1.37$ years. The mean menstrual cycle length was $27.8 \pm 3.14$ days, and the mean duration of menstrual flow was $4.8 \pm 1.14$ days. Thirty-seven (7.7\%) respondents were ignorant of their cycle length, while $29(6.0 \%)$ had irregular cycles. Premenstrual syndrome and dysmenorrhea were major menstrual issues, which resulted in 69 $(14.3 \%)$ and $59(12.2 \%)$ of respondents resorting to self-medication and absenteeism from school, respectively. Mothers were the main source of their daughters' adolescent education, while friends and mass media were the main source of contraceptive information. Though there was a high level (75.7\%) of awareness of contraceptive information among the girls, usage $(8.9 \%)$ was poor. Only eight (18.6\%) of the 43 respondents who had ever used modern contraception were adherent to modern contraceptives. Students who were more than 15 years old, attained menarche at 13 years or less, and whose families were of low socioeconomic classes were more likely to be sexually active.

Conclusion: The declining age at menarche, menstrual challenges, and poor reproductive health status of adolescent girls in this study have made menstrual issues and contraceptive adherence critical aspects of adolescent health care, especially when appropriate sources of reproductive health information were not fully harnessed. Therefore, there is an urgent need to establish adolescent-friendly clinics and include sexuality education in the curriculum of schools in this environment.

Keywords: menstrual pattern, contraception, reproductive health, adolescent girls, Nigeria

\section{Introduction}

Menarche is the onset of menstruation, and it is one of the most significant milestones in the reproductive life of a woman. It is the hallmark of adolescence, marking the transition from girlhood to womanhood. The mean age at menarche varies from population to population, and is known to be a sensitive indicator of various characteristics of populations, including nutritional status, geographical location, environmental conditions, and magnitude of socioeconomic inequalities in a society. ${ }^{1-4}$ For most females, it occurs between the ages of 10 and 16 years, with remarkable variation. ${ }^{3,4}$ Studies
Correspondence: Leonard Ogbonna Ajah Department of Obstetrics and Gynaecology, Federal Teaching Hospital, PMB I02, Abakaliki, Ebonyi 48000I, Nigeria

Tel +2348033920789

Email leookpanku@yahoo.com 
however suggest that menarche tends to appear earlier in life as the sanitary, nutritional, and economic conditions of a society improve. ${ }^{4,5}$ The normal range for menstrual cycles is between 21 and 35 days. While most periods last from 3 to 5 days, duration of menstrual flow normally ranges from 2 to 7 days. For the first few years after menarche, irregular and longer cycles are common. , $^{3,7}$

The incidence of teenage pregnancy and its complications in Nigeria is unacceptably high, and the incidence ranges from $2.25 \%$ to $21.9 \% .^{8-12}$ The majority of these teenage pregnancies are unintended and to single mothers. ${ }^{9}$ The high incidence of teenage pregnancy in our environment may be attributed to the ignorance of adolescents on their menstrual pattern and poor contraceptive practice. ${ }^{13,14}$ Therefore, knowledge of the length and variations in menstrual cycles and awareness and use of modern contraception is necessary for adolescent sexuality and education. More so, identification of deviations from normal menstrual cycles may help to guide in the clinical evaluation of young girls. It was for these reasons this study was undertaken. It was aimed at determining the age at menarche, menstrual pattern, awareness of modern contraception, and use of and adherence to modern contraception among secondary school adolescent girls in Abakaliki, southeast Nigeria. Findings from this study may help in bridging the knowledge gap in adolescent reproductive health in Nigeria.

\section{Subjects and methods}

Abakaliki is the capital of Ebonyi State, with an estimated population of 4.3 million according to the 2006 national census. It occupies a land mass of $5,935 \mathrm{~km}^{2}$. Approximately $75 \%$ of the population of Ebonyi State dwell in rural areas with farming as the major occupation. ${ }^{15}$ Abakaliki consists of two local government areas, namely Abakaliki and Ebonyi, out of 13 local government areas in Ebonyi State. This was a school-based cross-sectional study carried out between August and September 2012. Permission to interview the students and the comprehensive list of the secondary schools in Abakaliki were obtained from Ebonyi State Postprimary School Management Board. Abakaliki has 38 secondary schools: 16 boys' secondary schools, nine girls' secondary schools, and 13 mixed schools.

The study participants were selected through multistage sampling. Two secondary schools - Azuiyiokwu Girls' Secondary School and Ugwuachara Girls' Secondary School, Abakaliki - were initially selected through simple random sampling from the nine girls' secondary schools. Meetings were further held with these school authorities to discuss the study.
The girls were selected based on the World Health Organization definition of adolescent age: $10-19$ years. ${ }^{16}$ The questionnaire was pretested in a different secondary school, where the possibility of its self-administration by the students was ascertained. Then, with the list of the students in each school as a sampling frame, systematic random sampling was used to select the total number of samples allocated to each school. An initial random start was made, and thereafter every student with an odd serial number was selected. The number of samples allocated to each of the two girls' secondary schools was proportional to the population strength of students in these schools. The inclusion criteria comprised students who were between 10 and 19 years old, had attained menarche, had odd serial numbers in the school register, and had given their consent to participate in the study. Exclusion criteria were students who were either less than 10 years or more than 19 years old, had not attained menarche, had even serial numbers in the school register, and had declined consent to participate in the study. On the day of the study in each of these schools, the study was further explained to the students, and the research team distributed the questionnaires simultaneously to the students that met the inclusion criteria. The questionnaires were administered on August 8, 2012 at Azuiyiokwu Girls' Secondary School and September 5, 2012 at Ugwuachara Girls' Secondary School. These were the days the aforementioned school authorities gave approval for the questionnaires to be administered. Students who were sampled completed the questionnaires with relevant data in their classrooms and returned them to the research team immediately, in order to prevent interpersonal communication and influence of peers on individual responses among the girls. The information on the questionnaires covered the students' sociodemographic data, age at menarche, menstrual cycle pattern, premenstrual symptoms, history of sexual activity, awareness of modern contraception, use of modern contraception, and adherence to modern contraceptive use. Olusanya et al's social classification, ${ }^{17}$ using the educational status of the adolescent girls' mothers and their fathers' occupation, was adopted for this study. On determining the awareness of the respondents of modern contraceptives, they were asked if any of the modern contraceptives - condoms, pills, injectable contraceptives, intrauterine devices, implants - were known to them or not. Adherence to modern contraceptive use was defined as the use of modern contraceptives for every incidence of sexual activity. The arithmetic mean of the girls' ages at appearance of first menstruation was used to determine the age at menarche. The minimum sample size for the study was calculated based on the formula for estimating sample 
size for cross-sectional studies described by Daniel. ${ }^{18}$ With a $50 \%$ prevalence (for the sake of having a larger sample size), the minimum sample size was 384 . After adding an assumed attrition rate of $20 \%$, the calculated sample size was 461 .

Statistical analysis was done using the SPSS version 17 software (SPSS Inc, Chicago, IL, USA). The $\chi^{2}$ test was used for the discrete variables. A $P$-value of less than or equal to 0.05 was considered statistically significant. Ethical clearance for the study was obtained from the Ethics Committee of the Federal Teaching Hospital, Abakaliki. Informed written consent was obtained from the study participants who were at least 18 years old, or from next of kin for the participants who were under 18 years of age.

\section{Results}

A total of 500 questionnaires were administered in the two schools, and 482 (96.4\%) completely filled questionnaires were retrieved and analyzed. Table 1 shows the sociodemographic characteristics of the participants. The age range of the respondents was 13-19 years. The mean age at menarche was $13.31 \pm 1.37$ years. The majority $(71.2 \%)$ of the respondents were from low social class families (social classes III, IV, and V).

Table 2 shows the menstrual characteristics of the respondents. Over two-fifths (43.46\%) of the respondents had a cycle length between 27 and 29 days. The mean cycle length was

Table I Sociodemographic characteristics of respondents

\begin{tabular}{lll}
\hline Characteristics & Frequency $(\mathbf{n}=\mathbf{4 8 2})$ & Percentage \\
\hline Age (years) & 18 & \\
I3 & 24 & 3.7 \\
I4 & 146 & 5.0 \\
I5 & 130 & 30.3 \\
I6 & 118 & 27.0 \\
I7 & 32 & 24.5 \\
I8 & 14 & 6.6 \\
I9 & 2 & 2.9 \\
Age at menarche (years) & \\
9 & 12 & 0.4 \\
I0 & 43 & 2.5 \\
II & 57 & 8.9 \\
I2 & 133 & 11.8 \\
I3 & 144 & 27.6 \\
I4 & 75 & 29.9 \\
I5 & 16 & 15.6 \\
I6 & 23 & 3.3 \\
Social class of the parents & \\
I & 23 & 4.8 \\
II & 86 & 17.8 \\
III & 219 & 45.4 \\
IV & 124 & 25.7 \\
V & 30 & 6.2 \\
\hline
\end{tabular}

Table 2 Menstrual characteristics of respondents

\begin{tabular}{lcl}
\hline Characteristics & Frequency $(\mathbf{n = 4 8 2})$ & Percentage \\
\hline Menstrual cycle length (days) & \\
$21-23$ & $5 \mathrm{I}$ & 10.6 \\
$24-26$ & 57 & 11.8 \\
$27-29$ & 203 & 42.1 \\
$30-32$ & 75 & 15.6 \\
$33-35$ & 30 & 6.2 \\
Irregular cycle & 29 & 6.0 \\
Ignorant of cycle length & 37 & 7.7 \\
Menstrual flow duration (days) & \\
$2-3$ & 58 & 12.0 \\
$4-5$ & 310 & 64.3 \\
$6-7$ & 114 & 23.7 \\
Menstrual problems* & & \\
Dysmenorrhea & 309 & 64.1 \\
Premenstrual symptoms & 362 & 75.1 \\
Use of self-medication & 69 & 14.3 \\
Absenteeism from school & 59 & 12.2 \\
None & 89 & 18.5 \\
\hline
\end{tabular}

Note: *Students were free to tick more than one option.

$27.8 \pm 3.14$ days. None of the respondents had a cycle length less than 21 days. A total of $29(6.0 \%)$ respondents had an irregular cycle, while 37 (7.7\%) were ignorant of their cycle lengths. Most (79.5\%) of the respondents had a menstrual flow duration of between 4 and 6 days. The mean duration of menstrual flow was $4.8 \pm 1.14$ days. A total of $362(75.1 \%)$ of the adolescent girls had primary dysmenorrhea. This was followed by premenstrual symptoms. The premenstrual symptoms and dysmenorrhea were serious in that they resulted in $69(14.3 \%)$ and $59(12.2 \%)$ of the respondents resorting to self-medication and absenteeism from school, respectively.

Table 3 contains the sources of menstrual information, history of sexual activity, and awareness and practice of modern contraception among the adolescent girls. Mothers were the primary source of menstrual information in $81.5 \%$ of respondents. A total of 101 (21\%) of the students were sexually active. Even though $365(75.7 \%)$ of the students were aware of modern contraception, only $89(18.5 \%)$ of them were aware of emergency contraception and $43(8.9 \%)$ of them had ever used modern contraception. Only eight $(18.6 \%)$ of the 43 respondents who had ever used modern contraception were adherent to modern contraceptives. The major sources of information on modern contraception among these students were friends (58.9\%) and mass media (51\%). Only $15(16.9 \%)$ of the 89 students who were aware of emergency contraception had ever used it. The majority of these few emergency-contraceptive users used oral contraceptive pills. Table 4 shows the effect of sociodemographic characteristics on sexual activity. Students who were more 
Table 3 Source of menstrual information, history of sexual activity, and awareness and practice of modern contraception among the adolescent girls

\begin{tabular}{|c|c|c|}
\hline Characteristics & Frequency & Percentage \\
\hline \multicolumn{3}{|c|}{ Source of menstrual information* $(n=482)$} \\
\hline Mothers & 393 & 81.5 \\
\hline Friends & 77 & 16.0 \\
\hline Teachers & 49 & 15.6 \\
\hline Books & 15 & 3.1 \\
\hline None & 33 & 6.2 \\
\hline \multicolumn{3}{|c|}{ Prior history of sexual activity $(n=482)$} \\
\hline Yes & 101 & 21.0 \\
\hline No & 381 & 79.0 \\
\hline \multicolumn{3}{|c|}{ Awareness of modern contraception* $(n=482)$} \\
\hline Condom & 357 & 74.1 \\
\hline Oral contraceptive pills & 282 & 58.5 \\
\hline Injectable contraceptives & 111 & 23.0 \\
\hline Intrauterine devices & 36 & 7.5 \\
\hline None & 117 & 24.3 \\
\hline \multicolumn{3}{|c|}{ Source of information on modern contraception* $(n=365)$} \\
\hline Parents & 51 & 14.0 \\
\hline Friends & 215 & 58.9 \\
\hline Mass media & 186 & 51.0 \\
\hline Hospital & 43 & 11.8 \\
\hline Teachers & 27 & 7.4 \\
\hline Books & 33 & 9.0 \\
\hline \multicolumn{3}{|c|}{ Ever used modern contraception $(n=482)$} \\
\hline Yes & 43 & 8.9 \\
\hline No & 439 & 91.1 \\
\hline \multicolumn{3}{|c|}{ Adherence to modern contraception $(n=43)$} \\
\hline Yes & 8 & 18.6 \\
\hline No & 35 & 81.4 \\
\hline \multicolumn{3}{|c|}{ Types of modern contraception ever used $(n=43)$} \\
\hline Condoms & 28 & 65.1 \\
\hline Oral contraceptive pills & 13 & 30.2 \\
\hline Injectable contraceptives & 2 & 4.7 \\
\hline \multicolumn{3}{|c|}{ Awareness of emergency contraceptives* $(n=482)$} \\
\hline Yes & 89 & 18.5 \\
\hline No & 393 & 81.5 \\
\hline \multicolumn{3}{|c|}{ Ever used emergency contraception $(n=89)$} \\
\hline Yes & 15 & 16.9 \\
\hline No & 74 & 83.1 \\
\hline \multicolumn{3}{|c|}{ Emergency contraceptives used by the respondents $(n=17)$} \\
\hline Oral contraceptive pills & 13 & 86.7 \\
\hline Injectable contraceptives & 2 & 13.3 \\
\hline
\end{tabular}

Note: *Students were free to tick more than one option.

than 15 years old, had attained menarche at 13 years old or less, and whose families were of low socioeconomic status were more likely to be sexually active.

\section{Discussion}

The mean age at menarche in this study (13.31 \pm 1.37 years) was similar to other studies done in other centers. ${ }^{19,20}$ This was however less than the 15 years previously reported in a study in Ebonyi State. ${ }^{21}$ The reason for this difference could be
Table 4 Effect of sociodemographic characteristics on sexual activity

\begin{tabular}{|c|c|c|c|}
\hline \multirow[t]{2}{*}{ Characteristics } & \multicolumn{2}{|c|}{ Sexual activity } & \multirow[t]{2}{*}{$P$-value } \\
\hline & Yes & No & \\
\hline \multicolumn{4}{|l|}{ Age (years) } \\
\hline$\leq 15$ & 23 & 165 & $0.0002^{*}$ \\
\hline$>15$ & 78 & 216 & \\
\hline \multicolumn{4}{|c|}{ Age at menarche (years) } \\
\hline$\leq 13$ & 73 & 174 & $0.0001 *$ \\
\hline$\geq 14$ & 28 & 207 & \\
\hline \multicolumn{4}{|c|}{ Social class of the parents } \\
\hline$\leq \|$ & 14 & 95 & $0.02 *$ \\
\hline$\geq \mathrm{III}$ & 87 & 286 & \\
\hline
\end{tabular}

Note: *Statistically significant.

deduced from the fact that the previous study was conducted in rural areas, unlike this one, which was conducted in an urban area. Therefore, environmental and nutritional factors may have contributed to this difference. These environmental factors consist of a higher rate of infectious diseases, especially malaria, in this environment, lack of social amenities, low socioeconomic status, and ignorance that are common among rural dwellers when compared with urban residents. Previous studies have reported menarche to occur earlier in urban residents than in rural dwellers. ${ }^{19,22}$ Also, the mean age of menarche of $13.31 \pm 1.37$ years in this study is higher than the 12.5 years reported in the USA and Europe. ${ }^{23}$

The current study shows that early age at menarche increases the risk of early sexual activity, supported by a previous report from the USA. ${ }^{23}$ In our environment, where menarche marks the initiation of a woman's reproductive activity, early menarche leads to early coital activity and early marriages, ${ }^{24}$ with attendant complications of induced abortion, preeclampsia and eclampsia, obstructed labor, and vesicovaginal fistula. Some of these complications lead to maternal morbidity and mortality in young women who often are adolescents. Adolescent maternal mortality ratio in Sokoto, northwest Nigeria, is 5,415 per 100,000 live births and accounts for more than $23 \%$ of maternal mortalities in Abakaliki, southeast Nigeria. ${ }^{25,26}$ Moreover, the significant proportion of students who were sexually active at more than 15 years of age in this study was supported by a previous review by Olalekan, in which urban dwellers and Ibo women were less likely to have had early coitarche. ${ }^{27}$ Early sexual activity, common among the children of low socioeconomic parents in this study, may have been due to these girls lacking the basic needs of life, thereby necessitating their sexual activity as a means of socioeconomic survival. This is supported by a previous report in South Africa in which 
poor individuals, owing to lack of alternatives to earning a livelihood, indulged in transactional sex. ${ }^{28}$

The mean cycle length of $27.8 \pm 3.14$ days with the majority of the adolescent girls having a cycle length of between 27 and 29 days is similar to previous reports in sub-Saharan Africa. ${ }^{29,30}$ The students (13.4\%) who either had irregular menstrual cycles or were ignorant of their cycle length in this study were prone to teenage pregnancy if sexually active. The mean duration of menstrual flow of $4.8 \pm 1.14$ days in this study is similar to a previous report in Ghana. ${ }^{30}$

Dysmenorrhea occurring in $64.1 \%$ of this study respondents is less than the $72 \%$ and $74.4 \%$ previously recorded in Nigeria and Ghana, respectively. ${ }^{30,31}$ This however compares with $65 \%$ reported in the USA. ${ }^{32}$ Premenstrual syndrome, which occurred in $75.1 \%$ of the respondents, is less than the $85.5 \%$ reported in Calabar, Nigeria. ${ }^{33}$ Premenstrual syndrome and dysmenorrhea being so severe to warrant school absenteeism by $12.2 \%$ of the students in this study is similar to a report in India. ${ }^{22}$ The use of self-medication by $14.35 \%$ of the respondents in this study is however higher than the $7.13 \%$ reported in india. ${ }^{22}$ The reason for this difference may be differences in pain threshold between the groups of adolescents in the two regions. It might also be poverty, as the majority of respondents in this study belonged to low socioeconomic families. The unavailability of adolescent-friendly clinics in our environment may have contributed to self-medication among the respondents.

Education of adolescent girls on menstruation is important, because some misconceptions exist among them about menstruation. Some perceive it as a bad or strange thing, while others see it as a frightening or embarrassing experience. ${ }^{34}$ The majority $(81.4 \%)$ of the respondents in this study got their menstrual education from their mothers, similar to the findings of other studies in Nigeria and Ghana. ${ }^{15,30}$ Mothers are of critical importance and are also the preferred choice of education on menstrual issues and emotional support to daughters, since many daughters are uncomfortable discussing menstruation with their fathers. ${ }^{34}$ However, these girls are prone to getting wrong information from their mothers in view of the higher illiteracy rate among the mothers when compared to the fathers, especially in low socioeconomic classes, in Nigeria. ${ }^{35}$ In this study, experiencing menstruation might have been shocking to the $6.2 \%$ of the respondents who had not received any menstrual education. The right sources of menstrual education comprising teachers, health institutions, media, and books/magazines constituted a small proportion in this study. This shows that education on menstruation still needs to be improved upon by making use of the schools, health institutions, and print and electronic media, as it is not the sole responsibility of the family.

The finding that a fifth $(21 \%)$ of the respondents were sexually active was similar to the $26.8 \%$ reported by Adinma et al in Anambra State. ${ }^{36}$ The high proportion (75.7\%) of the adolescent girls aware of modern contraception in this study was more than the $38.2 \%$ reported by Adinma et al in Anambra State, but similar to the $81 \%$ reported in Ghana. ${ }^{36,37}$ Also, the $8.9 \%$ of the 365 students using modern contraception in this study was less than the $21 \%$ reported in Ghana. ${ }^{37}$ The $18.6 \%$ of these sexually active respondents who were adherent to modern contraception was less than the $35 \%$ previously reported in southeast Nigeria. ${ }^{38}$ This difference may have been because this study dealt purely with adolescent girls in secondary schools, unlike the previous study, which dealt with both male and female undergraduates. The low contraceptive usage and adherence among the sexually active adolescent girls in this study indicates that reproductive health providers and other stakeholders need to strategize on a formidable approach to reverse this unpleasant trend in this environment. Condom use, being the commonest known and used contraceptive method by the respondents, was similar to reports in other Nigerian and Ghanaian centers. ${ }^{35,36}$ Friends and mass media constituted the major source of contraceptive information in this study, consistent with a report from Ghana. ${ }^{36}$ With the high numbers reporting contraceptive information from friends, these students may not be getting the right information. The knowledge and use of emergency contraceptives by the sexually active adolescent girls in this study was very poor. This will therefore increase their risk of unwanted pregnancy with its associated complications.

This study was strengthened by the school-based design and its sampling technique. It was however weakened by the information on menstrual patterns and contraception, which was prone to recall bias.

\section{Conclusion}

There has been a gradual decline in the age at menarche in Ebonyi State. A good proportion of the adolescent girls resort to self-medication when they have severe premenstrual syndrome and dysmenorrhea. Though there was high level of awareness of modern contraceptive methods in this study, their usage by the sexually active adolescent girls was very poor. The right sources of menstrual and contraceptive information were not fully utilized by the adolescent girls. Therefore, there is an urgent need to establish adolescent-friendly clinics and include sexuality education in the curriculum of schools in this environment. This will not only help the 
adolescent girls have the right menstrual and contraceptive information but also increase their acceptability of reproductive health services.

\section{Disclosure}

The authors report no conflicts of interest in this work.

\section{References}

1. Ekele BA, Udoeyop EU, Otubu JA. Age at menarche amongst school girls in a high altitude Nigerian town. West Afr J Med. 1996;15(3): $170-172$.

2. Chumlea WC, Schubert CM, Roche AF, et al. Age at menarche and racial comparisons in US girls. Pediatrics. 2003;111(1):110-113.

3. Thomas F, Renand F, Benefice E, de Meeüs T, Cuegan JF. International variability of ages at menarche and menopause: patterns and main determinants. Hum Biol. 2001;73(2):271-290.

4. Kapowitz P. Pubertal development in girls: secular trends. Curr Opin Obstet Gynecol. 2006;18(5):487-491.

5. Abioye-Kuteyi EA, Ojofeitimi EO, Aina OI, Kio F, Alulo Y, Mosuro O. The influence of socioeconomic and national status on menarche in Nigerian school girls. Nutr Health. 1997;11(3):185-195.

6. Adams Hillard PJ. Menstruation in young girls: a clinical perspective. Obstet Gynecol. 2002;99(4):655-662.

7. ACOG Committee on Adolescent Health Care. ACOG Committee opinion no 349, November 2006: Menstruation in girls and adolescents: using the menstrual cycle as a vital sign. Obstet Gynecol. 2006;108(5):1323-1328.

8. National Population Commission [Nigeria] and ICF International. Nigeria Demographic and Health Survey 2013. Rockville (MD) and Abuja: National Population Commission and ICF International; 2014.

9. Onoh RC, Ezeonu PO, Anozie BO, et al. Outcome of teenage pregnancy at a tertiary hospital in Abakaliki southeast Nigeria. J Basic Clin Reprod Sci. 2014;3(1):22-26.

10. Nwobodo EI, Adoke KU. Obstetric outcome of teenage pregnancies at a tertiary care Hospital in Sokoto, Nigeria. Trop J Obstet Gynaecol. 2005;22(2):168-170.

11. Igwegbe AO, Udigwe GO. Teenage pregnancy: still an obstetric risk. J Obstet Gynaecol. 2001;21(5):478-481.

12. Loto OM, Ezechi OC, Kalu BK, Loto A, Ezechi L, Ogunniyi SO. Poor obstetric performance of teenagers: is it age- or quality of care-related? J Obstet Gynaecol. 2004;24(4):395-398.

13. Tayo A, Akinola O, Babatunde A, Adewunmi A, Osinusi D, Shittu L. Contraceptive knowledge and usage amongst female secondary school students in Lagos, southwest Nigeria. J Public Health Epidemiol. 2011; 3(1):34-37.

14. Lawan UM, Yusuf NW, Musa AB. Menstruation and menstrual hygiene amongst adolescent school girls in Kano, northwestern Nigeria. Afr $J$ Reprod Health. 2010;14(3):201-208.

15. Ezegwui HU, Onoh RC, Ikeako LC, et al. Investigating maternal mortality in a public teaching hospital, Abakaliki, Ebonyi State, Nigeria. Ann Med Health Sci Res. 2013;3(1):75-80.

16. World Health Organization. Young People's Health-A Challenge for Society. Report of a Study Group on Young People and Health for All by the Year 2000. Geneva: WHO; 1986.
17. Olusanya O, Okpere E, Ezimokhai M. The importance of social class in voluntary fertility control in a developing country. West Afr J Med. 1985;3(4):205-212.

18. Daniel WW. Biostatistics: A Foundation for Analysis in the Health Sciences. 7th ed. New York: John Wiley and Sons; 1999.

19. Thomas KD, Okonofua FE, Chibok O. A study of the menstrual patterns of adolescents in Ile-Ife, Nigeria. Int J Gynaecol Obstet. 1990;33(1):31-34.

20. Ikaraoha $\mathrm{C}$, Mbadiwe IC, Igwe CU, et al. Menarcheal age of secondary school girls in urban and rural areas of Rivers State, Nigeria. Online $J$ Health Allied Sci. 2005;4(2):1-4.

21. Umeora OU, Egwuatu VE. Age at menarche and menstrual pattern of Igbo women of southeast Nigeria. Afr J Reprod Health. 2008; 12(1):90-95.

22. Dambhare DG, Wagh SV, Dudhe JY. Age at menarche and menstrual cycle pattern among school adolescent girls in central India. Glob $J$ Health Sci. 2012;4(1):105-111.

23. Steingraber S. The Falling Age of Puberty in U.S. Girls: What We Know, What We Need to Know. San Francisco: Breast Cancer Fund; 2007.

24. Field E, Ambrus A. Early marriage, age of menarche, and female schooling attainment in Bangladesh. J Polit Econ. 2008;116(5):881-930.

25. Nwobodo EI, Panti A. Adolescent maternal mortality in north-west Nigeria. West Afr J Med. 2012;31(4):224-226.

26. Umeora OU, Esike CO, Egwuatu VE. Maternal mortality in rural Nigeria. Int J Gynaecol Obstet. 2005;88(3):321-322.

27. Olalekan AU. Geographical variations and contextual effects on age of initiation of sexual intercourse among women in Nigeria: a multilevel and spatial analysis. Int J Health Geogr. 2008;7:27.

28. Muula AS. HIV infection and AIDS among young women in South Africa. Croat Med J. 2008;49(3):423-435.

29. Zegege DT, Megabiaw, Mulu A. Age at menarche and the menstrual pattern of secondary school adolescents in northwest Ethiopia. BMC Womens Health. 2009;9:29.

30. Gumanga SK, Kwame-Aryee RA. Menstrual characteristics in some adolescent girls in Accra, Ghana. Ghana Med J. 2012;46(1):3-7.

31. Odujinrin OM, Ekunwe EO. Epidemiological survey of menstrual patterns amongst adolescents in Nigeria. West Afr J Med. 1991;10(3-4): 244-249.

32. Honston AM, Abraham A, Huang Z, D'Angelo LJ. Knowledge, attitudes and consequences of menstrual health in urban adolescent females. J Pediatr Adolesc Gynecol. 2006;19(4):271-275.

33. Antai AB, Udezi AW, Ekanem EE, Okon UJ, Umoiyoho AU. Premenstrual syndrome: prevalence in students of the University of Calabar, Nigeria. Afr J Biomed Res. 2004;7:45-50.

34. Koff E, Rierdan J. Preparing girls for menstruation: recommendations from adolescent girls. Adolescence. 1995;30(120):795-811.

35. Ojo A. Socio-economic situation. In: Africa Atlases (Nigeria). Paris: Les Editions; 2002:126-127.

36. Adinma JI, Agbai AO, Okeke AO, Okaro JM. Contraception in teenage Nigerian school girls. Adv Contracept. 1999;15(4):283-291.

37. Hagan JE, Buxton C. Contraceptive knowledge, perceptions and use among adolescents in selected senior high schools in the Central Region of Ghana. J Sociol Res. 2012;3(2):170-180.

38. Iyoke C, Ezugwu F, Lawani O, Ugwu G, Ajah L, Mba S. Peer-driven contraceptive choices and preferences for contraceptive methods among students of tertiary educational institutions in Enugu, Nigeria. Patient Prefer Adherence. 2014;8:1043-1050.
Patient Preference and Adherence

\section{Publish your work in this journal}

Patient Preference and Adherence is an international, peer-reviewed, open access journal that focuses on the growing importance of patient preference and adherence throughout the therapeutic continuum. Patient satisfaction, acceptability, quality of life, compliance, persistence and their role in developing new therapeutic modalities and compounds to optimize

\section{Dovepress}

clinical outcomes for existing disease states are major areas of interest for the journal. This journal has been accepted for indexing on PubMed Central. The manuscript management system is completely online and includes a very quick and fair peer-review system, which is all easy to use. Visit http://www dovepress.com/testimonials.php to read real quotes from published authors. 